
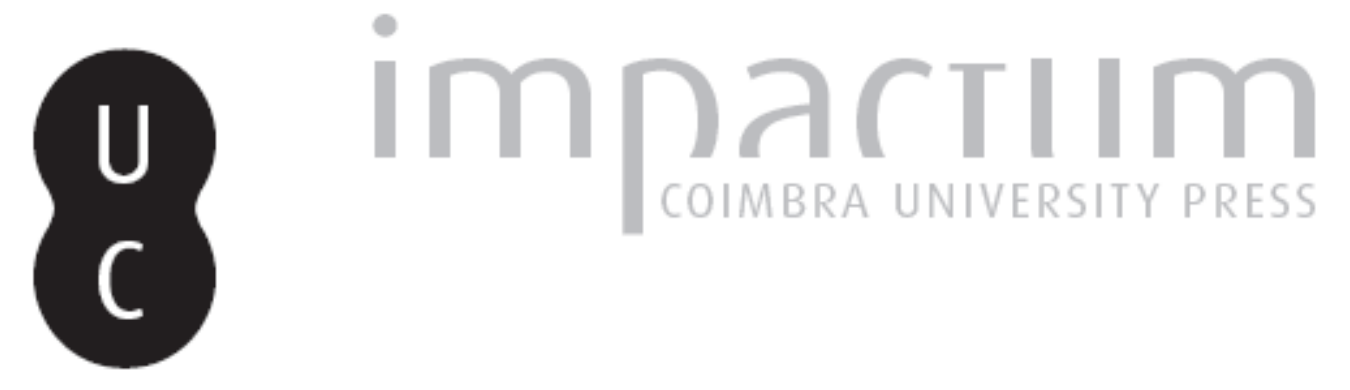

\title{
Estudos Italianos na Faculdade de Letras da Universidade de Lisboa
}

\section{Autor(es): $\quad$ Almeida, Maria João}

Publicado por: Imprensa da Universidade de Coimbra

URL persistente:

URI:http://hdl.handle.net/10316.2/42517

DOI:

DOl:https://doi.org/10.14195/0870-8584_5_4

Accessed : $\quad$ 26-Apr-2023 13:22:06

A navegação consulta e descarregamento dos títulos inseridos nas Bibliotecas Digitais UC Digitalis, UC Pombalina e UC Impactum, pressupõem a aceitação plena e sem reservas dos Termos e Condições de Uso destas Bibliotecas Digitais, disponíveis em https://digitalis.uc.pt/pt-pt/termos.

Conforme exposto nos referidos Termos e Condições de Uso, o descarregamento de títulos de acesso restrito requer uma licença válida de autorização devendo o utilizador aceder ao(s) documento(s) a partir de um endereço de IP da instituição detentora da supramencionada licença.

Ao utilizador é apenas permitido o descarregamento para uso pessoal, pelo que o emprego do(s) título(s) descarregado(s) para outro fim, designadamente comercial, carece de autorização do respetivo autor ou editor da obra.

Na medida em que todas as obras da UC Digitalis se encontram protegidas pelo Código do Direito de Autor e Direitos Conexos e demais legislação aplicável, toda a cópia, parcial ou total, deste documento, nos casos em que é legalmente admitida, deverá conter ou fazer-se acompanhar por este aviso.

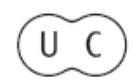




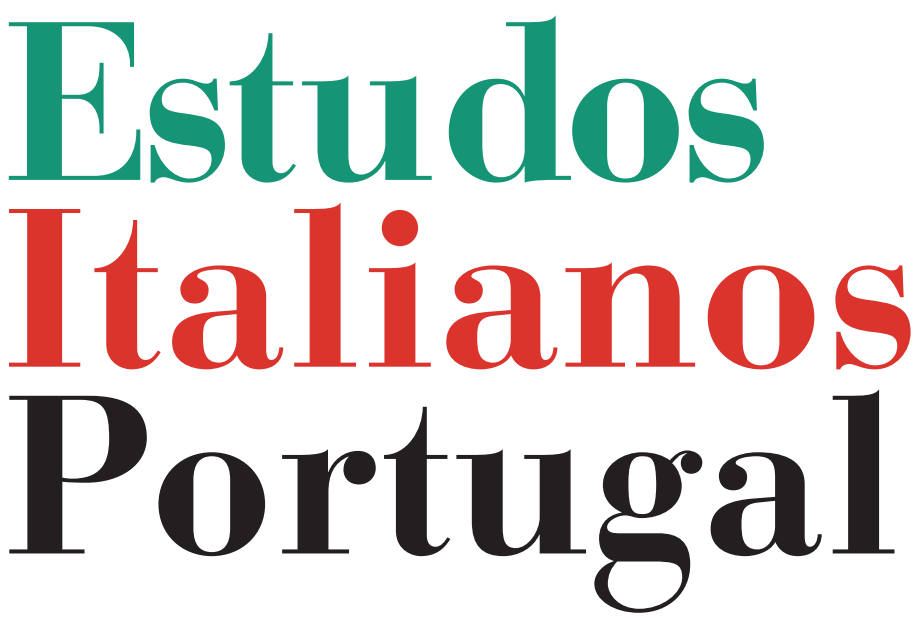

Instituto

Italiano

de Cultura

de Lisboa

Nova Série

$\mathrm{N}^{\mathbf{0}} 5$ 


\title{
UNIVERSIDADE DE LISBOA
}

\author{
ESTUDOS ITALIANOS NA FACULDADE \\ DE LETRAS DA UNIVERSIDADE DE LISBOA
}

Maria Jỗo Almeida*

O historial dos Estudos Românicos remonta, em Lisboa, ao Curso Superior de Letras instituído em 8 de Junho de 1859 por D. Pedro V. Mais tarde, já no século XX, no âmbito de uma grande reforma que perseguia a reorganização do ensino superior a nível nacional, o Decreto de 9 de Maio de $1911^{1}$ viria conferir ao antigo Curso o estatuto de Instituição consolidada, com a instalação da Faculdade de Letras de Lisboa, em simultâneo com a fundação da Faculdade de Letras de Coimbra (integrada na respectiva Universidade), estabelecendo a Filologia Românica, designada 2. ${ }^{\circ}$ Grupo, entre os restantes Grupos curriculares então criados.

No plano dos Estudos em Filologia Românica, com a duração de quatro anos (duração comum a todos os grupos), a Literatura Italiana comparecia emparelhada com a Literatura Espanhola numa única cadeira ministrada no $4 .^{\circ}$ ano em regime semestral. Uma meia dúzia de anos mais tarde, com a "primeira tentativa de correcção [...] da legislação de

* Licenciada e doutorada pela Faculdade de Letras da Universidade de Lisboa, lecciona Literatura e Cultura italianas nesta Faculdade desde 1990. Investigadora do Centro de Estudos Teatrais da UL, desenvolve actualmente investigação em história do teatro em Portugal e em literatura dramática italiana. Tem publicado artigos em livros e revistas e recentemente publicou o volume O teatro de Goldoni no Portugal de Setecentos (IN-CM, 2007).

1 D.G., n. ${ }^{\circ} 109$ de 1911. 
Onze"2, o Decreto-Lei n. ${ }^{\circ} 4651$, de 14 de Julho de $1918^{3}$ (em vigor a partir do ano lectivo de 1918-1919) viria apenas ampliar o regime de duração da cadeira de semestral para anual. O segundo passo lógico ocorreria passados oito anos com o Decreto n. ${ }^{\circ} 12$ 677, de 17 de Novembro de $1926^{4}$, que autonomizou as duas áreas cultural-literárias, uma e outra no $4 .^{\circ}$ ano do plano curricular de Filologia Românica.

Se com a reforma de 1930 nada de relevante haverá a assinalar no que respeita aos Estudos Italianos, a de $1957^{5}$ regista a inovação de agregar o ensino da Língua Italiana ao da respectiva Literatura Italiana numa só cadeira de duração anual, de leccionação deslocada para o $5 .^{\circ}$ ano ${ }^{6}$. Onze anos depois, com a legislação de $1968^{7}$, conhecida pela "Reforma de Veiga Simão", a cadeira de italianística, ainda com a mesma designação de Língua e Literatura Italiana, passa a obedecer ao estatuto de opção alternativa com a cadeira de Língua e Literatura Espanhola, integrada no $4 .^{\circ}$ ano curricular do Curso de Filologia Românica, situação que se manteve em vigor na Faculdade de Letras de Lisboa até ao ano lectivo de 1974.

$\mathrm{Na}$ sequência dos processos postos em andamento depois da Revolução de 25 de Abril, o 2..$^{\circ}$ grupo, de Filologia Românica, cindiu-se na FLUL, em obediência ao "critério científico", em duas unidades departamentais, então designadas de "Literatura" e de "Linguística", ao mesmo tempo que se criava um Instituto de Línguas destinado a ministrar o ensino das línguas vivas. Na prática, e na parte que respeita

2 A. H. de Oliveira Marques, "Notícia Histórica da Faculdade de Letras de Lisboa (1911-1961)", Separata de Ocidente,1970 p. 20.

3 D. G., I Série, n. ${ }^{\circ} 157,2{ }^{\circ}$ Suplemento de 14 de Julho de 1918.

4 D. G., I Série, n. ${ }^{\circ} 257$.

5 Dec. n. ${ }^{\circ} 41341$ de 30 de Outubro de 1957, D. G., I Série, n. ${ }^{\circ} 246$.

${ }^{6}$ Apesar da designação da cadeira, a língua italiana não foi ensinada pelo menos nos inícios da década de 60 de Novecentos, ao tempo em que a Prof. ${ }^{a}$ Ester de Lemos a leccionou e de acordo com o seu próprio testemunho.

7 Dec. n. ${ }^{\circ} 48627$ de 12 de Outubro de 1968, D.G., I Série, n. ${ }^{\circ} 241$. 
aos Leitorados das línguas românicas, o Instituto ficou sob a tutela do Departamento de Linguística.

As licenciaturas asseguradas pelos novos departamentos obedeciam a um escalonamento de níveis que, globalmente, por razões pedagógicas, se podem designar de $1 .^{\circ}$ - introdutório, $2 .^{\circ}$ - intermédio (formação geral), $3 .^{\circ}$ e $4 .^{\circ}$ - avançados (especialização) ${ }^{8}, 5 .^{\circ}$ - conclusão (do $5 .^{\circ}$ ano constava uma cadeira de natureza seminarial que visava preservar, por princípio, o espírito do trabalho individual da Tese de Licenciatura do currículo anterior).

Embora autónomas, e de currículos preenchidos em predominância de acordo com as respectivas áreas-objecto, as duas licenciaturas em Literatura e em Linguística não podiam deixar de continuar geminadas em vários pontos, entre outras razões, para além das de coerência curricular, pelas obrigações decorrentes da vocação da FLUL para a formação de futuros professores. E é a esse princípio de geminação que, na prática, se fica a dever a efectiva relacionação pedagógica entre as literaturas e respectivas línguas, agora integradas em distintos departamentos.

A nova licenciatura na área das Românicas (Literatura), designada "Licenciatura em Literatura", obedeceu a um plano curricular lançado no ano lectivo de 1974/1975 logo depois reajustado no ano de 1975/1976, oferecendo a cadeira de Literatura Italiana em regime de opção em dois anos e dois níveis (e assim também na cadeira de língua italiana realizada no Departamento de Linguística).

Embora sob a antiga designação de "Filologia Românica", a partir do ano lectivo de $1976 / 1977^{10}$, este perfil curricular e

8 Anuário da Universidade de Lisboa, Lisboa, U.L., 1971/72-1978/79, pp. 63-64.

9 A razão para não se adjectivar o termo "Literatura" tinha por fundamento o primado da literatura nacional numa Faculdade portuguesa.

${ }^{10}$ Em 1976, O Ministério da Educação do Primeiro Governo Constitucional impôs a substituição das designações das Licenciaturas em "Literatura" e "Linguística" pela antiga nomenclatura "Licenciatura em Filologia Românica", 
o regime de oferta das literatura e língua italianas manteve-se em vigor até à aplicação da reforma instituída pelo Decreto n. ${ }^{\circ}$ 53/78 de 31 de Maio que estabelecia o Curso de Línguas e Literaturas Modernas comportando diversas variantes.

Sem nos determos nas possibilidades combinatórias de diferentes áreas literárias propiciadas por este Decreto, nem nas alterações relativamente a reformas anteriores ${ }^{11}$, convém salientar que ele reforçava agora "a tendência modernizadora na organização dos cursos de Letras inaugurada em 1957, com a redução no plano curricular de cadeiras pertencentes a outros domínios culturais em benefício das áreas de especialização"12. Não se deve, no entanto, obliterar que, em substância, também aquela tendência modernizadora se encontra subjacente aos princípios norteadores das reestruturações ocorridas em 1974/1975 e 1975/1976, embora não suportadas por legislação oficial e apenas tacitamente aceites pelo Ministério da tutela.

Graças à reforma de 1978, pela primeira vez a área de Estudos Italianos, a par com outras áreas literárias estrangeiras, adquiriu uma importância expressiva nas Faculdades de Letras, com a criação das variantes de Estudos Portugueses e Italianos e de Franceses e Italianos. Na estrutura curricular de ambas figuravam quatro níveis de língua italiana distribuídos pelos quatro anos da Licenciatura, com a ressalva de, no

com distinção em "Ramo Literatura" e "Ramo Linguística". Fica ainda implícito que o Ministério da Educação também não reconhecia a existência dos dois Departamentos autónomos, só mais tarde objecto de legalização. Em termos oficiais, tudo se passa como se a Licenciatura em Línguas e Literaturas Modernas viesse substituir a antiga Filologia Românica.

11 O Diploma suprimia o grau de bacharel, fixado pela Reforma de 1957, e reduzia para 4 anos a duração da licenciatura, extinguindo também a dissertação obrigatória para pós-graduação.

12 Maria João Almeida e Cristina Sobral, "Letras Românicas na Faculdade de Letras: a sua história", in Se bem be lembro... [Letras românicas: ensino e investigação. Jornada de reflexão e debate], Lisboa, Departamento de Literaturas Românicas da FLUL, 1994, p. 17. 
último ano, o Italiano IV integrar as componentes de língua e linguística.

Quanto à Literatura Italiana, o seu ensino atingia os três níveis, a partir do $2 .^{\circ}$ ano da licenciatura. A Literatura Italiana III funcionava nas duas variantes acima nomeadas em opção alternativa com Literatura Portuguesa III e Literatura Francesa III, respectivamente. Segundo José da Costa Miranda, a divisão em três níveis estabelecida na literatura levou, na FLUL, a "uma caracterização, a bem dizer, propedêutica, da Literatura Italiana a nível do seu I ano. E a nível dos anos II e III de visões complementares, bem definidas, na sua formulação, pelo que uma visão global [...] [era] seguramente recolhida no final dos 3 anos de frequência da matéria, de acordo com o previsto nas duas variantes de Estudos Italia$\operatorname{nos}[\ldots]{ }^{\prime 13}$.

A aplicação desta mesma metodologia na distribuição das matérias pelos três níveis do ensino da Literatura Italiana teria continuidade após a entrada em vigor do estipulado em novo documento legal, a Portaria n. $.^{\circ} 852 / 87$ de 4 de Novembro ${ }^{14}$, proposta pela Universidade de Lisboa para a respectiva Faculdade de Letras. Preservando as variantes criadas pelo Decreto de 1978, esta reestruturação incidia fundamentalmente na variante de Estudos Portugueses e Franceses.

No que toca às variantes de Estudos Portugueses e Italianos e Franceses e Italianos da Licenciatura em Línguas e Literaturas Modernas ocorreram algumas alterações, consistindo a mais significativa na introdução da cadeira de Cultura Italiana, leccionada no $3 .^{\circ}$ ano. Além disso, no $4 .^{\circ}$ ano, era oferecida a opção por um dos dois conjuntos de disciplinas: Italiano IV e Literatura Italiana III ou Literatura Portuguesa III e Cultura Portuguesa II, na variante de Estudos

${ }^{13}$ José da Costa Miranda, Dados Biográficos. Dados Bibliográficos, Junho de 1992, p. 18.

${ }^{14}$ D.R., I Série, n. ${ }^{\circ}$ 254, de 4 de Novembro de 1987. 
Portugueses e Italianos, ou Literatura Francesa III e Cultura Francesa II, na variante de Estudos Franceses e Italianos.

No entanto, a novidade mais relevante da referida Portaria respeitava à criação do Ramo Educional "que integrou nos programas de ensino da Faculdade de Letras a formação especializada para os licenciados que se destinam ao Ensino Secundário" 15 . As cadeiras de Didáctica das Línguas do Ramo Educacional não contemplavam, porém, as línguas italiana e espanhola por não fazerem parte do currículo do Ensino Básico e Secundário.

Em $2002^{16}$, a FLUL procedia a uma nova reestruturação do Curso em Línguas e Literaturas Modernas que passava a compreender dez variantes unidisciplinares e seis bidisciplinares ${ }^{17}$, com planos de estudos organizados em regime semestral. No tocante à área italiana, desaparecia a variante de Estudos Franceses e Italianos, dando lugar à variante em Estudos Italianos, mantendo-se por outro lado a de Estudos Portugueses e Italianos. Os Quadros I e II dão conta das disciplinas da componente italiana nas duas variantes, permitindo também observar os aspectos em que os dois planos curriculares se diferenciam.

Quadro I - LLM - Estudos Portugueses e Italianos

\begin{tabular}{|l|l|l|}
\hline Literatura Italiana & 4 níveis & $3 .^{\circ}, 4 .^{\circ}, 5 .^{\circ}$ e $6 .{ }^{\circ}$ Semestres \\
\hline Cultura Italiana & $\begin{array}{l}2 \text { níveis obrigatórios } \\
1 \text { nível opcional }\end{array}$ & $\begin{array}{l}2 .^{\circ} \text { e } 3 .^{\circ} \text { Semestres } \\
5 .^{\circ} \text { Semestre }\end{array}$ \\
\hline Língua Italiana & 8 níveis & Um por Semestre \\
\hline Linguística Italiana & $\begin{array}{l}3 \text { níveis obrigatórios } \\
1 \text { nível opcional }\end{array}$ & $\begin{array}{l}5 .^{\circ}, 6 .^{\circ} \text { e } 7 .^{\circ} \text { Semestres } \\
8 . .^{\circ} \text { Semestre }\end{array}$ \\
\hline
\end{tabular}

15 Maria João Almeida e Cristina Sobral, cit.

16 Deliberação n. ${ }^{\circ}$ 78/2002, D.R., II Série, n. ${ }^{\circ}$ 25, de 30 de Janeiro de 2002.

17 Na reforma de 1978, a Licenciatura em Línguas e Literaturas Modernas comportava onze variantes, todas bidisciplinares à excepção dos Estudos Portugueses. 
QuAdro II - LLM - Estudos Italianos

\begin{tabular}{|l|l|l|}
\hline Literatura Italiana & 5 níveis & $3 .^{\circ}, 4 .^{\circ}, 5 .^{\circ}, 6 .^{\circ}$ e $7 .^{\circ}$ Semestres \\
\hline Cultura Italiana & $\begin{array}{l}\text { 2 níveis obrigatórios } \\
1 \text { nível opcional }\end{array}$ & $\begin{array}{l}2 .^{\circ} \text { e } 3 .^{\circ} \text { Semestres } \\
5 .^{\circ} \text { Semestre }\end{array}$ \\
\hline Língua Italiana & 8 níveis & $U$ m por Semestre \\
\hline Linguística Italiana & 4 níveis & $3 .^{\circ}, 4 .^{\circ} 5 .^{\circ}$ e $6 .^{\circ}$ Semestres \\
\hline
\end{tabular}

Com a integração da FLUL no Espaço Europeu do Ensino Superior e na Sociedade do Conhecimento, o Departamento de Literaturas Românicas, no quadro das alterações introduzidas pelo chamado "Processo de Bolonha", enveredou por uma profunda reformulação dos currículos, com entrada em funcionamento a partir do ano lectivo de 2006/07. No plano estrutural, teve-se em vista a organização dos estudos na perspectiva da sucessão de ciclos de graduação (Licenciatura, Mestrado, Doutoramento), implicando a generalização do regime semestral, o encurtamento da Licenciatura de 4 para 3 anos e a flexibilização das preferências dos estudantes quanto à composição dos elencos curriculares. Neste contexto, os Estudos Italianos beneficiaram de um assinalável alargamento da oferta de disciplinas, quer em Literatura, quer em Cultura, distribuídas por níveis, conforme se indica no Quadro III.

Actualmente, após os reajustamentos curriculares cuja implementação se foi reconhecendo ser necessária, o elenco das disciplinas da área de Italianística (cf. Quadro IV) veio permitir a realização de um Minor em Estudos Italianos (30 ECTS - 5 cadeiras, com uma apreciável margem de opcionalidade), oferecido nas Licenciaturas de Línguas, Literaturas e Culturas e de Artes e Humanidades.

No que diz respeito aos docentes incumbidos da leccionação das cadeiras da área de italianística (na FLUL), ao longo de mais de seis décadas, no período compreendido entre 1914/1915 e a criação do Curso de Línguas e Literaturas Modernas, as informações coligidas permitem-nos identificar nomes, sem 
QUADRO III - Estudos Italianos

\begin{tabular}{|c|c|}
\hline Disciplinas de nível I & $\begin{array}{l}\text { Introdução à Literatura Italiana } \\
\text { Introdução à Cultura Italiana }\end{array}$ \\
\hline Disciplinas de nível II & $\begin{array}{l}\text { Literatura Italiana Medieval } \\
\text { Literatura Italiana Clássica } \\
\text { Literatura Italiana Moderna } \\
\text { Literatura Italiana Contemporânea } \\
\text { Literatura Italiana: Poesia Lírica } \\
\text { Literatura Italiana: Narrativa } \\
\text { Literatura Dramática Italiana } \\
\text { Dante } \\
\text { Petrarca e o Petrarquismo } \\
\text { Cultura Italiana: Tradições e Modelos } \\
\text { Cultura Italiana: Crises e Vanguardas } \\
\text { Renascimento Italiano } \\
\text { Marcos da Cultura Italiana }\end{array}$ \\
\hline
\end{tabular}

QuAdro IV

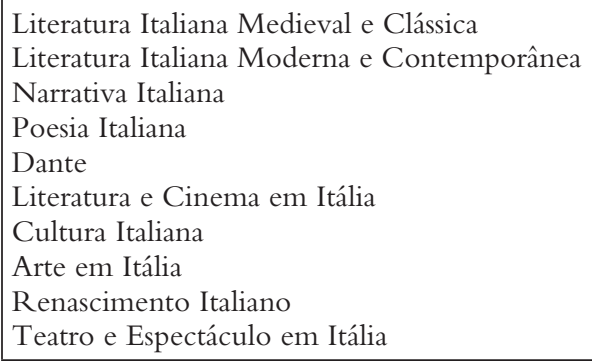

rigor exaustivo, tais como: Joaquim Teófilo Fernandes Braga, Agostinho José Fortes, Vitorino Nemésio, Manuel Rodrigues Lapa, Hernâni Cidade, Agostinho Celso de Azevedo Campos, António José Saraiva, Giuseppe Carlo Rossi, Maria de Lourdes Belchior Pontes, Luigi Federzoni, Luís Filipe Lindley Cintra, Maria Ester de Lemos, José Vitorino de Pina Martins, Maria Lúcia Lepecki e José da Costa Miranda ${ }^{18}$.

18 Para a identificação dos docentes nas datas compreendidas entre os anos lectivos de 1914/15 e 1960/61 recorremos a A. H. de Oliveira Marques, cit., p. 54. 
Em tempos mais recentes, depois do ano lectivo de 1978/1979 até à presente data, a docência das cadeiras de Literatura e Cultura Italianas inclui os nomes de José da Costa Miranda (até à aposentação em 1996) e dos docentes do Departamento de Literaturas Românicas, de formação especializada e competentes em matérias da área de italianística, Maria João Almeida, Isabel Almeida, João Figueiredo e Clara Rowland.

Segundo os dados disponíveis, a frequência das cadeiras da área dos Estudos Italianos atingiu o ponto máximo nas décadas de 1980 e 1990. Entre finais de uma década e cerca de meados da seguinte, a disciplina de Literatura Italiana I, por ex., contava com um efectivo de discentes que rondava a ordem da centena, com duas turmas regra geral asseguradas pelo mesmo docente. Desde há alguns anos, vem-se registando uma diminuição do número de estudantes das cadeiras de Literatura e Cultura Italianas (devido à tendência geral da redução de alunos em Humanidades), merecendo no entanto relevo o facto de a área continuar a ser atractiva, conforme se deduz pelo número de estudantes que a escolhem em regime de opção.

Como as restantes áreas departamentais, a de Estudos Italianos dispõe de um Instituto de Cultura, fundado com a Reforma de 1957, sede de um considerável acervo bibliográfico sempre actualizado ao longo dos anos. Para esse enriquecimento, no sentido de uma especialização nas diversas vertentes dos Estudos Italianos, muito contribuiu o empenho e dedicação daquele que foi seu Director por largos anos, o Professor José da Costa Miranda ${ }^{19}$. Graças às suas diligências, e para além das aquisições pela Instituição, pôde o Instituto beneficiar de doações de proveniência

19 Depois da aposentação do Professor Costa Miranda, a direcção do Instituto foi desempenhada, sucessivamente, pelas Professoras Maria Lucília Pires e Isabel Almeida, sendo actualmente dirigido por Maria João Almeida. 
diversa, quer de entidades italianas (Secção Cultural da Embaixada Italiana em Lisboa; FIAT, entre outras), quer de portuguesas (Fundação Calouste Gulbenkian), com destaque para o importante espólio de italianística, integrado no início da década de 90 de Novecentos, por doação do antigo docente da Faculdade de Letras, Prof. Giacinto Manuppella.

Devido à remodelação das infra-estrutras da FLUL que a contemplou com uma nova biblioteca, o Fundo Giacinto Manuppella e o restante espólio bibliográfico do Instituto fazem parte do acervo da Biblioteca da Faculdade. Mas essa integração não prejudicou, nem a função, nem a visibilidade e operatividade do Instituto. Tanto as suas funções tradicionais de apoio científico aos estudantes se encontram beneficiadas pela logística da Biblioteca da Faculdade, como vem prosseguindo e ampliando a sua acção em eventos científicos, individualmente e/ou em colaboração.

Muitas vezes em colaboração com o Instituto Italiano de Cultura de Lisboa, o ICI da Faculdade de Letras foi dando corpo a iniciativas científico-pedagógicas em forma de lições, palestras, seminários, com a participação de professores italianos e nacionais. Para além da sua qualidade de eventos culturais públicos também se destinavam a complementar as actividades lectivas das matérias italianas.

De acordo com o novo estatuto do ICI (após a integração do seu espólio na Biblioteca da FLUL), vem-se acentuando a anterior política de eventos de alcance científico e cultural, individualmente e em colaboração. Refira-se, neste domínio, a realização em parceria com o Centro de Estudos de Teatro da FLUL do Encontro "Futurismo - 100 anos depois", entre Março e Abril de 2010, e a Jornada "Diálogos Luso-Italianos", patrocinada pelo Instituto Italiano de Cultura em Portugal, levada a efeito no dia 14 de Setembro de 2010 . 
Em conclusão deste breve memorando em torno do historial da italianística na FLUL, desejamos vivamente agradecer os preciosos testemunhos, informações e apoios concedidos por: Prof ${ }^{a}$ Cristina Almeida Ribeiro (Dir. ${ }^{a}$ do Dep. de Literaturas Românicas da FLUL), Prof. ${ }^{a}$ Isabel Rocheta (docente do Dep. de Literaturas Românicas da FLUL), Prof. ${ }^{a}$ Maria Lúcia Lepecki (docente aposentada do Dep. de Literaturas Românicas da FLUL), Prof. Alberto Carvalho (docente aposentado do Dep. de Literaturas Românicas da FLUL), Prof. ${ }^{a}$ Ester de Lemos (antiga docente da FLUL), Dr. Ricardo Reis (Secretário Coordenador da FLUL), Dr. Carlos Sirgado (Chefe dos Serviços de Alunos da UL), Dr. ${ }^{a}$ Maria Leal Ramos Vieira (Directora do Serviço de Documentação e Publicações da UL), D. Maria de Lurdes Gaspar Lourenço (funcionária dos Serviços Académicos da FLUL).

\section{Bibliografia}

Aguilar, Manuel Busquets de, O Curso Superior de Letras (1858-1911), Lisboa, 1939.

Almeida, Maria João e Cristina Sobral, "Letras Românicas na Faculdade de Letras: a sua história", in Se bem be lembro... [Letras românicas: ensino e investigação. Jornada de reflexão e debate], Lisboa, Departamento de Literaturas Românicas da FLUL, 1994.

Anuário da Universidade de Lisboa, Lisboa, Universidade de Lisboa, 1971/72 - 1978/79.

Marques, H. de Oliveira, "Notícia Histórica da Faculdade de Letras de Lisboa (1911-1961)”, Separata de Ocidente, Lisboa, 1970.

Miranda, José da Costa, Dados Biográficos. Dados Bibliográficos, Junho de 1992.

Revista da Universidade de Lisboa, Ano II, n. ${ }^{\circ}$ 5, Lisboa, Reitoria da Universidade de Lisboa, 1988. 